Ensayo basado en la Conferencia magistral realizada en la Comisión Económica para América Latina y el Caribe (CEPAL), en Santiago de Chile, el 29 de abril de 2014, en el marco de la Trigésimo tercera Cátedra Raúl Prebisch.

\title{
El desarrollo ayer y hoy: idea y utopía
}

\author{
Rolando Cordera Campos
}

RESUMEN

La crisis de la globalización ha actualizado la reivindicación por el desarrollo como un complejo proceso que involucra cambios sociales e institucionales, así como formas diversas de aprendizaje democrático. Puesta en los márgenes de la discusión académica y política internacional, la economía política del desarrollo puede volver por sus fueros en la medida que la academia y los propios comandos políticos de la economía se vean impelidos a reflexionar sobre el largo plazo. La economía política del desarrollo debe hermanarse con la política para reconfigurar el significado del interés general, alineándolos tras objetivos de libertad, justicia y democracia. Tales pueden ser las coordenadas cuyo fin consista en hacer de la globalización, que es apertura e interdependencia, un vector activo en el cultivo de la densidad nacional como elemento indispensable para pensar críticamente la realidad y, como lo enseñó y practicó Prebisch, darle a la historia un curso creador de futuro.

PALABRAS CLAVE

CLASIFICACIÓN JEL
Desarrollo económico, globalización, Raúl Prebisch, modelos de desarrollo, igualdad, derechos humanos, democracia, bienestar social, derecho al desarrollo, América Latina

B15, B31, O10, O54

Rolando Cordera Campos es profesor emérito en la Facultad de Economía de la Universidad Nacional Autónoma de México (unam), México. cordera@unam.mx 
Los males que aquejan a la economía latinoamericana no responden a factores circunstanciales o transitorios. Son expresión de la crisis del orden existente y de la escasa aptitud del sistema económico - por fallas estructurales que no se ha sabido o no se ha podido corregir-para lograr y mantener un ritmo de desarrollo que responda al crecimiento de la población y a sus exigencias de rápido mejoramiento.

Raúl Prebisch

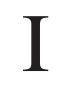

\section{Introducción ${ }^{1}$}

El objetivo de este ensayo es presentar una reflexión libre sobre la idea del desarrollo, ayer y hoy. Asentada en este bello y entrañable país de poetas, educadores y luchadores por la democracia y la justicia social, la CEPAL mantiene su empeño en dar rigor y robustez al pensamiento latinoamericano comprometido con el progreso colectivo y la afirmación permanente, siempre actualizada, de América Latina en el mundo como un conjunto de Estados y naciones articuladas por la noción de soberanía. Pero también en un proyecto inmanente de cooperación humana para sostener y dar sentido al discurso de transformación productiva con equidad, ciudadanía y democracia que ahora recoge, como coherente colofón, una arriesgada convocatoria a hacer de esta la hora de la igualdad.

Como lo enseñara Prebisch, estos requisitos sustanciales para la evolución política del continente se organizan en torno de la idea, la teoría y la práctica del desarrollo. En ellos convergen una compleja sumatoria de mudanzas productivas, inserciones y reinserciones en el turbulento escenario de la economía mundial, de movilizaciones sociales y de compromisos de largo alcance para darle al poder visiones progresistas e imponerle los obligados límites del cuidado y respeto de los derechos humanos en un horizonte de ciudadanía en expansión.

Agenda histórica nunca concluida, porque esa es, entre otras, la condición de que nuestra utopía de América, de la que hablara Alfonso Reyes, no caiga en ilusiones fútiles y se despliegue en perspectivas realistas

\footnotetext{
${ }^{1}$ Acudo a esta cita emocionado. Gracias a todos quienes participaron en tan generosa distinción; mi reconocimiento cariñoso a Alicia Bárcena y mi respeto afectuoso a quienes, con su empeño intelectual y laboriosa entrega a la investigación y la reflexión sobre el desarrollo, han honrado la gran empresa educativa y transformadora a que convocaran don Raúl, el gran hereje diría Furtado, y los miembros de la orden cepalina del desarrollo.
}

y realizables de fortalecimiento cívico y progreso social justo y efectivo.

Como ambicioso y consistente innovador, Prebisch insistió en la necesidad de que los legionarios del desarrollo latinoamericano - economistas, sociólogos, politólogos, ahora biólogos y ecólogos — se dotaran y enriquecieran del ejercicio de una autonomía intelectual emanada de la crítica. Su infatigable compromiso con la búsqueda de rutas para superar bloqueos y laberintos, le llevó a una incansable tarea de creación de instituciones. Fue Raúl Prebisch un hombre de acción en el diseño y discusión de la política económica, de exploración paciente -así como audaz y permanente- de un desarrollo latinoamericano auténtico y robusto, no encerrado en efímeras autosatisfacciones, presto a imaginar y arriesgar caminos propios, de invención y adaptación, y no de adopción o imitación acrítica, "extra lógica", como diría don Alfonso Reyes.

Su visión conserva un carácter contemporáneo, actual: polaridad y tensión en el sistema global centroperiferia; centralidad decisiva del progreso técnico y, por ende, del conocimiento y la cultura; nexos dinámicos, creativos, entre comercio exterior y expansión productiva; inversión extranjera, sustitución de importaciones, interdependencia virtuosa; términos de intercambio de las materias primas como oportunidad, pero también como pesadilla. Antes que todo, como nos lo han dicho una y otra vez en estas cátedras: pensar críticamente la realidad; disolver el pensamiento autodesignado hegemónico; darle a la historia un uso transformador, creador de futuro.

Me he nutrido de las reflexiones de quienes me han antecedido en el uso de esta espléndida tribuna y lamento no poder hacerles la justicia que merecen. Todos ocupados y preocupados por el imperioso desafío del desarrollo, conscientes de que solo puede lograrse apelando a una ética pública que dé sentido histórico, a la vez que 
práctico, a la democracia, al Estado constitucional, a los derechos humanos y a la justicia. Celso Furtado, Joseph Stiglitz, Fernando Henrique Cardoso, Rubens Ricupero, Dani Rodrik, Enrique Iglesias, Tulio Halperín-Donghi, Fernando Savater, Aldo Ferrer, José Antonio Ocampo, Danilo Astori, Luiz Gonzaga Belluzzo, inscritos por derecho propio en la legión que fundaran don Raúl y los suyos en pos de las mejores plataformas del pensamiento social y político latinoamericano y universal.

Tratar de impulsar reflexiones que vayan más allá de la bruma impuesta por esta primera gran crisis global; no ha sido ni será fácil vislumbrar una nueva fragua donde la economía y la política, al fundirse, lleven a perfilar nuevas estrategias para un desarrollo extraviado y unas democracias atribuladas: las ideas-fuerza o los paradigmas que han inspirado o justificado, según el caso, los diferentes proyectos de transformación del Estado y las estructuras productivas con miras a cambios sociales y económicos nunca han sido neutros.

Como lo advertía Rosanvallon (1989) en su estudio sobre el desarrollo del keynesianismo en Francia, a diferencia de las teorías propias de las ciencias físicas y naturales, las ideas económicas no se confrontan en un plano homogéneo de conocimiento. Siempre está presente un filtro político e ideológico que no es inocuo, como no lo son la presencia y acción de las burocracias del Estado, en especial las financieras; los intereses y agentes sociales; los poderes de hecho asentados en la riqueza; los portentosos conglomerados mediáticos de alcance global.

El sentido común, construido en y desde las esferas mediáticas y en los centros dominantes de pensamiento y formación de opinión, no se presta a fomentar el surgimiento de nuevas ideas sobre el gobierno del Estado y la economía. Más bien, conforma una trinchera poderosa, a la vez que difusa, contra ellas y su conversión en paradigmas alternativos.

También sirve como soporte de revisiones o renovaciones cosméticas de las corrientes predominantes del pensamiento cuya reproducción no es lineal, sino a través de los enclaves institucionales e ideológicos donde tienen lugar el conflicto social y la confrontación política permanentes.

Los acontecimientos políticos e intelectuales que han acompañado a la crisis actual, o que esta ha puesto sobre la mesa, constituyen lecciones de particular interés para nosotros, instalados en el privilegiado observatorio global y regional que es la CEPAL. Sobre todo si lo que nos congrega es la convicción de que urge construir una visión que, sin soslayar ni mitificar las enormes mudanzas estructurales y mentales que ha traído la globalización, se proponga explícitamente la construcción de estrategias inscritas en propósitos de renovación cultural, redistribución social, ampliación democrática y cuidado estricto, a la vez que creativo, del entorno.

Estamos ante nuevos hitos, complejas y tensas convivencias entre política y democracia, Estado y mercado, economía y sociedad. En un primer momento, los descalabros financieros convirtieron en anatema lo que hasta ayer era dogma (la autorregulación global y la eficiencia de los mercados), mientras que los poderes del tiempo y del mundo parecían empeñados en reactualizar lo que era visto como anacronismo (el papel activo de los Estados). Pero el mundo no se quedó ahí, para dar lugar a la conquista de un futuro distinto a partir de la crisis. Más bien, esos mismos poderes y sus derivaciones en la academia y los medios parecieron optar por una nueva vuelta al pasado.

Por esto y por numerosas otras razones, tenemos y tendremos mucho que revisar y reflexionar y hacerlo ya, sin prisa, pero sin pausa. Reconocer que hablamos desde una disciplina "avergonzada" por su ineficacia ante la Gran Recesión, como ha dicho lord Skidelsky, el gran biógrafo de Keynes, para desde ahí recuperar, y pronto, un sentido común que solo da el cultivo de la historia y el compromiso con la crítica.

En palabras de Prebisch, hay que "buscarse una nueva racionalidad, que no se base únicamente en objetivos económicos y sociales, sino también en objetivos fundamentalmente éticos" (Dosman, 2011). Esta afirmación puede extenderse a la incorporación de una ética pública (Cortina, 2013) que reivindique la solidaridad como valor moderno, así como la aceptación de buenas dosis de humildad para nuestro ejercicio de revisión y actualización histórico-conceptual. Como ha dicho Ocampo (2001): "Creer que 'ya sabemos lo que se debe hacer' es simplemente una expresión de arrogancia de los economistas (...) los resultados frustrantes de las reformas y el descontento social deberían convencer a muchos sobre la necesidad de repensar la agenda de desarrollo".

La economía política del desarrollo que queremos debe probar que está dispuesta a hermanarse con la política para reconfigurar el significado del interés general o del bien común, alineándolos por objetivos de libertad, justicia y democracia. Solo así podremos recuperar visiones de largo plazo cuyas divisas sean el crecimiento económico sostenido, a la vez que la centralidad de la equidad para la igualdad social y la creación de una ciudadanía democrática sostenible. Tales pueden ser las coordenadas maestras para hacer de la globalización, que es apertura e interdependencia, un 
vector activo para el cultivo de la densidad nacional que Ferrer (2010) concibe como indispensable para despejar el gran dilema del desarrollo en el mundo global.

La conjunción de la democracia y la economía con la globalización no ha sido ni será un viaje sencillo; pero, a fin de cuentas, de lo que se trata es de reasumir la aventura del cambio social, como ayer, cuando se pensaba que apropiarse del futuro para reinventarlo a través del desarrollo y la planeación era no solo una "fantasía organizada", como la llamara Celso Furtado, sino una utopía realista.

En sus palabras: "Lo que caracteriza al desarrollo, es el proyecto social subyacente. El crecimiento se funda en la preservación de los privilegios de las elites que satisfacen sus ansias de modernizarse. Cuando el proyecto social da prioridad a la efectiva mejora de las condiciones de vida de la mayoría de la población, el crecimiento se convierte en desarrollo. Pero este cambio no es espontáneo. Es fruto de la expresión de una voluntad política" (Furtado, 2004).
De manera esquemática, en la sección II de este documento se tratan algunos asuntos considerados críticos a objeto de revisar, actualizar y poner en perspectiva la idea del desarrollo cultivada por la CEPAL y sus pensadores. Cuestiones que tienen que ver con las tensiones entre crisis, democracia y desigualdad en la perspectiva de la urgencia de recuperar el desarrollo, como concepto y proceso centrales, tal como se plantea en la sección III. Asimismo, en la cuarta sección se aborda aquello que se estima como el gran trípode moderno: derechos, reclamo de desarrollo y de justicia para llegar a lo que - a través de la crisis global actual— se considera como el gran compromiso institucional que le da materialidad a la idea del desarrollo: el Estado de bienestar, que es abordado en la sección V. Para terminar en la sexta sección con una visión, a la vez crítica y propositiva, del cambio estructural ocurrido en México con miras a acelerar el proceso de globalización de su economía. Por último, en la sección VII se ofrecen las principales conclusiones del ensayo.

\section{II}

\section{Crisis, democracia, desigualdad:} volver a lo básico

La crisis actual puso en entredicho la globalización del mundo que se aceleró a fines del siglo XX. Si se está o no en los albores de cambios más profundos en un orden mundial que no pudo constituirse como tal al final de la Guerra Fría; si se pueden o no restaurar sus tejidos y mecanismos fundamentales en torno del libre comercio o la movilidad de capitales; si las economías políticas nacionales son capaces de absorber positiva y productivamente el gran tema de la migración, son algunos de los dilemas que rodean la antigua tensión entre la economía y la política, la democracia, el mercado y el desarrollo.

El conflicto social, agudizado por la crisis, se despliega sobre las posibilidades de recuperación económica y, al acentuarse la desigualdad, amenaza con desembocar no solo en un nuevo malestar en la cultura, en este caso en la democracia, sino en lo que el PNUD (2004) advertía hace unos años para América Latina: un desencuentro entre la economía y la política, acentuado por una agudización de la cuestión social que se extiende como un malestar no solo en sino con la democracia recuperada en la región.
Se requiere, por lo dicho anteriormente, entender que la relación democracia-desigualdad refiere a una dimensión que trasciende la esfera económica y se asienta, por peso propio, en el campo de lo que podríamos llamar "política de Estado", la que —al implementarse o apenas proponerse- conduce a preguntar por las capacidades organizativas, institucionales y fiscales, políticas e ideológicas de los Estados que vivieron las traumáticas mudanzas del cambio neoliberal y que ahora pugnan por reconvertirse en Estados democráticos constitucionales propiamente dichos.

La reforma del Estado adquiere aquí una impronta estructural que no puede abordarse con expedientes reduccionistas, como el de su minimización, pero tampoco de engrosamiento sin más de los aparatos públicos. Lo que urge es repensar la centralidad estatal como conjunto institucional, interfaz con el resto del sistema transnacional de Estados y como relación compleja de la sociedad con el poder y sus maneras de constitución y ejercicio.

La cuestión de las jerarquías y de la constitución, ejercicio y renovación del poder es inseparable de las otras dos vertientes primordiales de toda economía 
política: la división del trabajo y la distribución de los frutos del esfuerzo social empeñado en la producción. La coordinación social depende, al final de cuentas, de cómo se aborda dinámicamente el despliegue de este triángulo maestro de sociedades, mercados y Estados. Se trata de una relación siempre en tensión, al borde de la inestabilidad, que se ha agudizado con el avance de los procesos de la globalización del mundo y la economía.

Por lo pronto, habrá que decir que nos quedan la política y los pactos que mediante ella puedan erigirse, para buscar formas y mecanismos que eviten que tales tensiones se vuelvan contradicciones insolubles y las formaciones nacionales se disuelvan en el torbellino global. Desde esta apelación a la política, podemos añadir que una vinculada expresamente con la igualdad tiene que cimentarse en una cultura cívica y una ética pública congruentes con sus fines y motivaciones, para aspirar a ser estable y duradera en el tiempo. La crisis de la igualdad es un hecho social total y no solo de ingresos, accesos u oportunidades.

¿Cómo, entonces, construir sociedades más democráticas, igualitarias y solidarias? ¿Puede durar la democracia en condiciones de aguda desigualdad y pobreza? ¿Hasta dónde es posible hablar de democracia con el mantenimiento y reproducción de la inequidad económica y social? ¿Cómo lograr cambios sustanciales que contribuyan a reducir los niveles de desigualdad y exclusión y a garantizar el acceso y el ejercicio universales de derechos sociales?

Los anteriores cuestionamientos no son meros ejercicios intelectuales. Son preguntas que embargan el pensamiento social y político latinoamericano. Después de años de recuperación democrática y de casi dos décadas de crecimiento económico, insuficiente en un principio, luego relativamente alto, sostenido en algunos casos, aunque sin cambios significativos en la distribución del ingreso, los problemas que la desigualdad le plantea a la democracia siguen soslayándose.
Podría decirse que la desigualdad se convierte en una cultura, no de la pobreza que estudiaron los antropólogos, sino de la riqueza concentrada, de la satisfacción diría Galbraith (2011), que aparte de dificultar los diseños políticos modernos, constituye un desafío frontal a las normas y formas éticas y políticas que deberían derivar del desarrollo democrático.

De lo anterior podríamos extraer una primera respuesta a nuestras preguntas: la cohesión social es fruto del desarrollo democrático de las sociedades, pero a la vez se ha vuelto una condición para que los gobiernos renueven su legitimidad y la democracia concite la participación y el apoyo de la ciudadanía. Condición primordial para una promisoria inserción en la globalidad, la cohesión se ve de pronto sometida al fuego cruzado del reclamo democrático de redistribución y de exigencia de equilibrios e incentivos a la acumulación y las competitividades dinámicas para mantenerse y avanzar en el mercado global. De estas tensiones se pasa sin previo aviso a someter a la soberanía a nuevos y desmedidos requisitos en apariencia inapelables.

De ahí la necesidad de entender la relación entre democracia y desigualdad como una ecuación que debe resolverse en positivo en favor de la igualdad, y como un requisito para que la política produzca gobernanza basada en la legitimidad. Por ello es que en las sociedades modernas, o en aquellas que quieren serlo, la conversación entre el desarrollo y la igualdad deja de ser un producto del azar o de leyes naturales y pasa a ser una cuestión política. El imperativo categórico de la democracia, de la que hablara Fernando Henrique Cardoso, encuentra aquí una dura prueba.

Frente a estos dilemas, la economía tiene que evolucionar a una economía política del desarrollo inspirada en el equivalente actual, moderno y global de los sentimientos morales de Adam Smith para, desde ahí, recuperar el desarrollo.

\section{III}

\section{Actualidad del desarrollo}

El desarrollo, como proceso de cambio social, político y económico, requiere de un buen funcionamiento de las instituciones, pero también implica una reestructuración básica de valores y actitudes. Asimismo, los bloqueos y diques estructurales para dicho cambio solo pueden encararse desde una plataforma activa de diseños y estrategias que rompan la estabilidad, fruto de esos bloqueos, para desembocar en constelaciones político- 
institucionales capaces de dar cauce a las energías desatadas por el cambio económico y social. Nada de esto, por lo demás, está garantizado de antemano.

El desarrollo moderno, en especial el que arranca con el fin de la Segunda Guerra Mundial, pronto se desplegó en un proceso institucional y político complejo y diverso que hoy es inseparable de la aspiración a crear un régimen universal de derechos. Esta noción, a su vez, remite a la de justicia integral, porque si la igualdad que promete la democracia se limita a las leyes o a las urnas, resulta del todo insuficiente para asegurar y extender la justicia social. El desarrollo entendido como creación y expansión de derechos; los derechos asumidos como justicia y libertad; la política pensada como acción y compromiso permanente con el código democrático, son las coordenadas imprescindibles para construir una nueva agenda y una macroeconomía reformada para el desarrollo y la igualdad.

En la CEPAL se ha hablado con propiedad de las diversas conexiones entre la macroeconomía y la economía del desarrollo. Estas relaciones están en el núcleo histórico del pensamiento cepalino. Sin embargo, no es redundante recordar lo que Ros (2013) ha advertido: que la economía del desarrollo, como la del crecimiento, “también nació siendo macro", y el mismo crecimiento económico debe ser visto como "un proceso de cambio estructural más que como una mera acumulación de factores combinada con cambio técnico".

Lo que la crisis nos plantea como imperativo, entonces, es la adopción de una política macroeconómica para el desarrollo y no solo para la estabilización financiera o de los precios, como ha señalado, entre otros, Moreno Brid (2013). Al poner bajo su atención variables como el crecimiento económico sostenido y el empleo, esta macroeconomía tendrá que inducir estrategias mayores y políticas específicas, de amplio espectro, explícitamente dirigidas a promover la redistribución social y recuperar los horizontes de igualdad que inspiraran la construcción de los Estados sociales.

Como lo ha planteado la CEPAL (2012) en su segunda entrega sobre la igualdad y lo ha expuesto Ocampo (2011): una condición ineludible es la realización de transformaciones productivas que impulsen la diversificación estructural y abran la puerta a desempeños dinámicos que puedan sustentar y combinarse con objetivos de equidad, universalización de derechos y expansión de la ciudadanía.

Por su parte, Amartya Sen (2003) ha insistido en que el concepto de desarrollo no puede limitarse a incrementos del producto nacional bruto ( $\mathrm{PNB}$ ) o del ingreso personal, la industrialización, el progreso tecnológico o la modernización social. Estos son logros importantes - a menudo cruciales - pero su valor debe estar relacionado con el efecto que tienen en las vidas y libertades de las personas a quienes atañen. El desarrollo como libertad que propone el Nobel indio debe extenderse al desarrollo como igualdad. Un continuиm complejo y hasta azaroso que, sin embargo, no debe someterse a soluciones arbitrarias de continuidad impuestas por contingencias económicas o financieras mal leídas y peor entendidas, o por abiertos y desfachatados intereses concentrados de clase y poder.

\section{IV}

\section{Trípode moderno: desarrollo, derechos y justicia}

El "derecho al desarrollo" antecede a la ola actual de universalización de los derechos humanos. Sin embargo, es cada día más claro que el desarrollo moderno es inseparable de la aspiración a crear un régimen universal de derechos. Solo así, postulan las Naciones Unidas, la civilización podrá volver realidad los viejos sueños de la Ilustración y los compromisos actuales de la democracia.

La idea del desarrollo como progreso, como "estar al día", a la par de lo que se considera lo más avanzado, es tan vieja como la modernidad; forma parte no solo del pensamiento clásico de las ciencias sociales, sino de la experiencia política internacional de los dos últimos siglos. No por casualidad, Adam Smith, padre fundador de la economía política, en 1776 intituló su obra más célebre Una investigación sobre la naturaleza y causas de la riqueza de las naciones.

Sin embargo, la preocupación por este proceso central de la modernidad no se volvió universal y estratégica sino hasta la segunda mitad del siglo XX. Antes, solamente formaba parte del arsenal de los estadistas del "círculo íntimo" de las naciones poderosas. Puede decirse que se trataba de un etnocentrismo sin cimientos sólidos, pero con una retórica eficaz que propició una soberbia sin freno y un cosmopolitismo 
selectivo: la "carga del hombre blanco" de la que hablara Kipling. Configuraciones excluyentes que encontraron su inicial gran revés en la Primera Guerra Mundial y su secuela de crisis económicas y descalabros de las democracias, avasalladas en varias latitudes por los fascismos y otras tentaciones totalitarias.

Con la Segunda Guerra Mundial el mundo experimentó un gran punto de inflexión histórico; si bien el conflicto bélico fue tremendamente destructivo, también resultó ser una enorme "licuadora" para las culturas y las experiencias humanas. En más de un sentido, se trató de la primera gran vivencia masiva de la globalización que puso en contacto a hombres de todas las latitudes, desplazándolos por territorios hasta entonces desconocidos para el habitante promedio, e introdujo a poblaciones enteras de las regiones atrasadas en lo que hoy llamaríamos la modernidad.

Es cierto que esto se hizo a través de la destrucción más violenta imaginable, pero sus lecciones fueron asimiladas por las élites emergentes —o en formación-y pronto fueron plasmadas en reclamos de descolonización, mejoramiento material, independencia nacional y avance social. El derecho al desarrollo empezó a plantearse como un reclamo universal, y la autonomía de los Estados y la soberanía de las naciones como componentes indisolubles del nuevo orden. De ahí la importancia de la Conferencia de Bandung (1955), ya que fue la primera ocasión en que se propagó por el globo la noción de un "tercer mundo" como idea-fuerza.

Los combatientes del mundo avanzado y sus familias, agudizada y enriquecida su memoria de las crisis de entreguerras por la experiencia dolorosa de la conflagración, empezaron a entender la protección social y la presencia activa del Estado como un derecho colectivo e individual no solo adquirido, sino exigible. Así, desde los centros del nuevo sistema internacional que surgía de la guerra se (re)descubría, racional y políticamente, la centralidad del desarrollo que, para serlo, tendría que estar acompañado de equidad y bienestar social.

En América Latina, en condiciones y con perspectivas diferentes, se empezó a vivir también el sueño del desarrollo: industrialización dirigida por el Estado y sustitución de importaciones; urbanización, clases medias emergentes y masivo reclamo de inclusión; nuevas maneras de vincularse con la economía mundial que se reconformaba, formaron parte del arsenal de políticas y visiones al que convocaran Raúl Prebisch y sus compañeros de la CEPAL, cuyo discurso pretendía combinar racionalidad económica con necesidad histórica mediante la política y la acción del Estado, tareas que se reivindican como centrales para la evolución económica.
Sin "adueñarse" del centro del escenario político y social, como ocurre ahora, la democracia era avizorada como la plataforma institucional y de participación social que podía conjugar productivamente una interdependencia dinámica entre un Estado con nuevas demandas y una sociedad que cambiaba y procuraba nuevas formas de afirmación soberana ante el resto del mundo.

De este modo, el planeta entero se dio a la búsqueda explícita del crecimiento económico, considerado un factor indispensable para el bienestar social y la consolidación de las democracias. Con el triunfo de la Revolución China y la independencia de la India, pareció que una parte significativa de la población mundial podría concretar estas expectativas, no solo en cuanto al progreso material para todos, sino mediante capacidades nacionales para trazar trayectorias históricas novedosas, incluso radicalmente distintas de las conocidas hasta entonces como exitosas.

La capacidad de la Unión Soviética para "saltar hacia adelante" en medio de la gran depresión de los años treinta y resistir la invasión nazi, contribuyó a convertir el desarrollo en la idea-fuerza del mundo que emergía. Vector central en este empeño fue la planeación que, al ser adoptada por el ímpetu desarrollista y de reconstrucción posbélica, dejó su rigidez centralista y empezó a verse como una vía factible para emprender nuevas combinaciones entre Estado y mercado, e implementar una economía mixta creativa y sostenible.

En esta circunstancia, "Prebisch preconizaba un 'régimen inteligente', o un Estado sagaz. Si bien el Estado debía apoyar la industrialización, la economía en su conjunto debía seguir impulsada por el sector privado para que prosperara" (Dosman, 2001). Por lo tanto, la intervención estatal (extrema, agregaría) era tan perjudicial como la aceptación ingenua de la doctrina de la ventaja comparativa. "No hay que sofocar al sector privado — advertía Prebisch-. Un sector privado y un clima de inversión saludables eran esenciales para el éxito económico y una estrategia de inversión acertada".

Cuando la Guerra Fría impuso la ideología como factor determinante de la política mundial, el desarrollo también empezó a verse como una variable estratégica en el enfrentamiento bipolar. Entonces, se le propuso como alternativa a la revolución y como una manera (más efectiva y gradual) de realizar una redistribución del ingreso y la riqueza. Paradójicamente, fue al calor de este conflicto que muchos países intentaron rutas de progreso económico y social que pretendían recoger lo mejor de las dos experiencias que entonces se presentaban como opciones únicas. 
Las "terceras vías" de aquellos años fueron poco efectivas, pero la idea misma de usar y explorar tradiciones e idiosincrasias como plataformas y condiciones iniciales para el desarrollo económico quedó en la memoria histórica e institucional. Ahora, en medio de las tormentas de la globalización y su crisis, reclama un lugar central en el inventario de las opciones de políticas e instituciones para el desarrollo. Así, por lo demás, lo vislumbró el Prebisch reformador de la cuestión social e incansable pionero de la planificación y la economía mixta (Halperin, 2008).

Durante décadas, el mundo se desarrolló en un equilibrio delirante de destrucción mutua. Como paradigma reinaban el pleno empleo y la protección social, y en el mundo en desarrollo el crecimiento económico sostenido y la industrialización se veían como las vías para arribar a plataformas de progreso que se concretaban en los Estados de bienestar. Intervenciones regulares del Estado en las decisiones y los procesos económicos; aprovechamiento intenso de los fondos externos de ayuda, préstamos o inversión; protección y hasta invención del precario empresariado doméstico, todo esto y más se puso en juego en esos años bajo las divisas del crecimiento y el pronto arribo a actividades del más alto valor agregado posible.

La acumulación de capital físico y la inversión productiva, junto con la industrialización ampliada de las economías y la urbanización acelerada de las sociedades, fueron los vectores de la gran transformación de la segunda mitad del siglo XX. La eficacia política y la creación material sostenida fueron puestas por sobre lo que ahora se llaman "políticas correctas". El cometido era la expansión, mientras que la distribución de los frutos del crecimiento y la eficiencia económica (micro o macro) era vista, en todo caso, como un efecto del proceso general.

Los resultados de este esfuerzo no se corresponden con lo que después se trataría de imponer como "leyenda negra" del desarrollo. Desaciertos y excesos los hubo pero, en lo fundamental, aquellos fueron tiempos de crecimiento productivo y cambio social; y si bien la predominancia de formas corporativas de participación y control social arrinconaba a la democracia y propiciaba toda suerte de abusos, corrupciones y concentraciones de riqueza y poder, también es cierto que las posibilidades de ampliar las esferas de la reproducción social crecían y podían materializarse en bienes e instituciones.

Años más tarde, con las convulsiones de fines del siglo XX, resumidas en la implosión del comunismo soviético, la globalización de las finanzas y, en menor medida, de la producción y el comercio, sobrevino un radical cambio paradigmático. En lugar de pleno empleo y protección social se impusieron la lucha contra la inflación, la estabilidad financiera y la reducción de los compromisos del Estado con el bienestar y la justicia social. Todo ello, presentado como el boleto de entrada al nuevo mundo global del mercado mundial unificado y la democracia representativa: el nuevo orden prometido por el Presidente Bush después de la primera guerra del Golfo, habría de convertirse con el tiempo más en una hipótesis de trabajo que en un curso efectivo de evolución de la sociedad internacional.

En varios países las nociones de ajuste, pago de la deuda externa, revisiones y reversiones de los Estados se volvieron criterios y políticas inmutables, en consonancia con lo que a la postre se llamó el consenso de Washington. Se dio así una profunda, en buena parte pasiva, contrarreforma económica del Estado que afectaría sensiblemente el corazón de la economía política del propio Estado.

Más que un desarrollo "esquivo", del que hablara en su momento Wolfe (1976), o errático y en declive como el experimentado en los años setenta con sus oscilaciones y rupturas y la "estanflación", lo que el mundo empezó a vivir a partir de las últimas décadas del siglo pasado fue un extravío: no solo en términos de ritmos de expansión o estabilidad macroeconómica, sino de aquellos valores y criterios que dieron lugar a la gran visión de un desarrollo entendido como expansión de derechos y cambio social.

De esta forma, con su catálogo de recomendaciones destinadas a "volver a lo básico", que en esta lógica es la centralidad del mercado, el consenso de Washington pretendió redefinir el perfil del mundo y asegurar la implantación de un nuevo orden global. Sustenta su propuesta la visión de una economía de mercado irrestricta — que se pretende universal y racional— que reduce al Estado a su mínima expresión, hasta volverlo una entidad puramente instrumental.

Se fue tan lejos en este empeño por "corregir" lo que se tenía como excesos y adiposidades del Estado y sus tareas, y en la revisión de ideas y proyectos, que incluso se pretendió hacer desaparecer del mapa de las prioridades internacionales la idea misma del desarrollo. Como quiera que se haya entendido en los centros del poder internacional y de formulación de ideas, el desarrollo siempre refiere a cambio y desequilibrios, cuando lo que imperaba era el mandato de los equilibrios, y en el mejor de los casos de la estática comparativa.

Con todo, en una ironía sin duda cruel de la historia mundial, en 1986 —en el ojo del huracán de las crisis financieras que anunciaban la llegada del torbellino 
globalizador — se logró que las Naciones Unidas adoptaran el derecho al desarrollo como uno de los derechos humanos inalienables. El desarrollo, se afirmaba, era la realización de todos los derechos civiles, económicos, sociales y culturales contenidos en la Declaración Universal de los Derechos Humanos. Y luego, en 1993, se consignó el derecho y el deber de los Estados de formular políticas nacionales de desarrollo destinadas al mejoramiento constante del bienestar de toda la población, asegurar la igualdad de oportunidades para todos y todas en el acceso a los recursos básicos, la educación, los servicios de salud, los alimentos, la habitación y el empleo, y a una justa distribución del ingreso.

Las disonancias a las que daba lugar el gran cambio del mundo que comenzaba, entraban en contradicción con la lógica del desarrollo, comprometida con recoger y traducir políticamente las demandas profundas de las mayorías planetarias que había echado a correr el otro gran deterioro desatado por la Segunda Guerra Mundial. De esto hablaba y meditaba, con notable anticipación y agudeza proverbial, Bobbio (1991), el gran pensador de Turín: "El reconocimiento y la protección de los derechos humanos están en la base de las constituciones democráticas modernas. La paz es, a su vez, el presupuesto necesario para el reconocimiento y la protección de los derechos humanos, tanto en los Estados como en el sistema internacional. Al mismo tiempo, el proceso de democratización del sistema internacional, que es el camino obligado para la realización del ideal de la 'paz perpetua' en el sentido kantiano de la palabra, no puede avanzar sin una extensión gradual del reconocimiento y protección de los derechos humanos por sobre los Estados.

"Derechos humanos, democracia y paz son tres elementos necesarios del mismo movimiento histórico: sin derechos humanos reconocidos y protegidos no hay democracia; sin democracia no existen las condiciones mínimas para la solución pacífica de los conflictos". Se puede decir que el derecho al desarrollo se nutre de los derechos económicos, sociales, culturales y ambientales, los que - no obstante las dificultades para concretarlos en el tiempo y en el espacio- deben verse como derechos que responden a los valores "globales" de la igualdad, la solidaridad, la no discriminación. Además, como sostiene las Naciones Unidas, ellos deben entenderse como universales, indivisibles y progresivos, además de interdependientes con los derechos civiles y políticos. Estos derechos socioeconómicos, culturales y ambientales aluden a objetivos y metas cuyo cumplimiento depende de las respectivas capacidades de las economías y de los Estados para darles no solo realidad, sino sostenibilidad. De ahí la insistencia, en algunos medios y círculos del poder, en verlos sobre todo como "derechos programáticos" cuyo cumplimiento depende de la viabilidad financiera o la coyuntura económica.

Sin embargo, su valor estriba más bien en que definen un ordenamiento jurídico-institucional que contribuye a arraigar orientaciones éticas cada vez más integradas a los propósitos colectivos y, por lo tanto, a las decisiones económicas y políticas dirigidas a superar las carencias, disminuir las desigualdades y proteger el medioambiente.

Reconocer a los derechos económicos, sociales, culturales y ambientales (DESCA) como parte indisoluble de las demandas de la ciudadanía jurídica y política, que Occidente reivindica como agenda triunfadora, conduce a plantearse el tema de la "tercera" ciudadanía, la ciudadanía social, estudiada por Bottomore y Marshall (2005). Su realización depende no solo de la generación de recursos materiales e institucionales suficientes, sino de cómo se distribuyan; y asimismo de que esta indivisibilidad de los derechos se implante como un reflejo esencial de los Estados y las sociedades.

En esto radica la densidad social que las democracias puedan lograr y de ello depende su calidad y duración como orden político fundamental. Así, la evolución de la ciudadanía en y con la globalización podría desplazarse desde el reclamo elemental de los derechos y las libertades democráticas y cívicas hasta la participación social en la construcción de economías políticas organizadas para la equidad y la igualdad, no solo por su nivel y ritmo de crecimiento, sino por el marco político y ético de exigencias que podría erigirse en torno de su centralidad. Entonces, el derecho al desarrollo devendría en un efectivo desarrollo de los derechos.

Empero, la globalización incompleta en sus alcances y contenidos, y ahora en crisis, lejos está de haber arrojado los resultados esperados. "Pese a los grandes esfuerzos realizados, los resultados de los nuevos 'patrones de desarrollo' son insatisfactorios. Esta situación va acompañada, para una gran parte de la población, de una escasa titularidad de sus derechos ciudadanos, que en el terreno jurídico y político se manifiesta en una desigualdad fundamental en el acceso a la justicia y una escasa participación en las decisiones políticas, en tanto que en las esferas económica y social se traduce en disparidad de oportunidades, inestabilidad laboral, bajos ingresos, impedimentos a la movilidad social, particularmente para las mujeres, desconocimiento de la diversidad étnica y cultural, e indefensión frente al infortunio" (CEPAL, 2000).

$\mathrm{Si}$ el derecho al desarrollo es inseparable de la justicia social, también puede verse como un derecho 
ciudadano fundamental y su realización es (debería ser) una prioridad para los Estados. De ahí deriva la necesidad de reconocer como derecho universal de las naciones la autonomía y capacidad para decidir sus pautas de desarrollo económico y distribución social, así como las formas de inscribirse en el mercado y la economía globales.
La igualdad, su extensión a formas de vida y cultura distintas a las conocidas, su vinculación con la democracia y una participación social más amplia conformarían la gran extensión del desarrollo, el horizonte y el mandato ético que nos ha propuesto la CEPAL. Tal es, debería ser, también el futuro de los Estados reformados para asegurar el bienestar.

\section{V}

\section{Estados de bienestar:}

\section{el gran compromiso histórico}

La circunstancia ominosa de la situación actual debería conducir a replantear los términos de la estrategia que llevó a la crisis. La innovación financiera imaginada como "big bang"; la codicia como cultura; la entronización del individualismo posesivo más extremo, entre otros, impulsan hoy a la necesidad redescubierta de su regulación. Junto con esto, la exigencia de contar con Estados fiscales fuertes y dinámicos es insoslayable: solo así se podrá intentar reeditar la combinación de crecimiento económico con estabilidad social.

Ahora, de cara a las disrupciones de la globalización convertidas en extensa crisis desde 2008, se (re)descubre el papel y el carácter del Estado en las economías, así como la urgencia por establecer nuevas y más eficaces formas de conexión entre la economía y la sociedad, atendiendo a la agudización de la cuestión social debida al cambio estructural globalizador y su crisis. Así lo propugna la CEPAL (2010 y 2012) en sus publicaciones recientes, donde se argumenta y se aboga por "dotar al Estado de mayor capacidad para redistribuir recursos y promover la igualdad (...) También, por un Estado de bienestar y no un Estado subsidiario, que avance hacia una estructura tributaria y un sistema de transferencias que privilegie la solidaridad social". Se sostiene entonces la centralidad de la política y del Estado para forjar pactos sociales extensos, a la vez que profundos, y para reformar al Estado y dotarlo de capacidades efectivas de promoción y coordinación social para la política.

El retorno del Estado a través de su reforma y la expansión de la política democrática, ciertamente seguirá sujeto a las limitaciones emanadas de las historias mundiales y nacionales, así como de las experiencias específicas, idiosincráticas, de las formaciones nacionales. Surge una dialéctica: frente al "demasiado Estado", el reclamo libertario de afirmación de la individualidad y de la autonomía; frente a una excesiva condensación de la política en partidos y parlamentos, las nuevas figuras políticas, ideológicas y culturales en un sentido amplio, emanadas de la globalización y del fin de la bipolaridad: sociedad civil, derechos humanos como mandato universal, cosmopolitismo democrático, ciudadanía global.

Pero, por otra parte, sigue vigente la advertencia del gran Polanyi (1992) en su análisis del colapso de la primera fase de la globalización: si el mercado pretende subordinar a la sociedad, terminará por destruir sus propios cimientos. "La idea de un mercado que se regula a sí mismo es una idea puramente utópica. Una institución como ésta no podía existir de forma duradera sin aniquilar la sustancia humana y la naturaleza de la sociedad".

El papel del Estado social, capaz a la vez de generar externalidades tecnológicas e institucionales sin renunciar a su compromiso histórico, es fundamental y no contingente para toda esta etapa de recuperación del crecimiento y recentralización del desarrollo. La nueva agenda para reformar el Estado no tiene nada que ver con un discurso de tabula rasa o un imposible regreso al pasado. Procura ser el fruto de una recapitulación conceptual y de experiencias, una puesta al día ilustrada por la historia para emprender un nuevo curso que abra cauces a un proyecto de inclusión social y consolidación democrática.

La reforma del Estado que la época reclama para encaminarse a un cambio fundamental debe tener como eje maestro una reforma social del propio Estado. Este no puede reducirse a satisfacer demandas específicas de cambios en el uso de los recursos o la conformación institucional; para ser un componente y un catalizador de una efectiva y radical "reforma de las reformas", el Estado debe centrarse en la reconstrucción de los tejidos y procesos sociales básicos que implica, a su vez, una redistribución del poder, un reacomodo radical de las 
relaciones y pesos entre las esferas de la economía y su comando en la asignación de los recursos y la distribución de los ingresos y la riqueza; como también, sin duda, en la esfera del poder político y administrativo y en la propia división del trabajo dentro del Estado.

En consecuencia, existe la necesidad ineludible de contar con Estados fiscales, fuertes y dinámicos. Solo así podrá intentarse la delicada y veleidosa combinación de dinamismo económico con redistribución y estabilidad social y macroeconómica. Como señala la CEPAL (2010): "La igualdad de derechos provee el marco normativo y sirve de fundamento a los pactos sociales que se traducen en más oportunidades para quienes tienen menos. La agenda de igualdad exige (...) generar una institucionalidad que permita consolidar un orden democrático y participativo (...) Dicha agenda pasa por construir un gran acuerdo económico-social cuya expresión última es el pacto fiscal (...) este implica una estructura y una carga tributarias que permitan fortalecer el rol redistributivo del Estado y de la política pública a fin de garantizar umbrales determinados de bienestar (...)".

En esta tesitura, la evaluación del cambio estructural realizado a fines del siglo XX se impone como una tarea necesaria para revisar la política económica y cuestionar varias de las certezas inamovibles sobre las que se han fundado sus discursos. Frente a la dictadura del ajuste financiero y el equilibrio fiscal, entendido unívocamente como "déficit cero", se pueden imaginar nuevas maneras de estructurar los Estados nacionales, otras combinaciones entre la apertura externa y la promoción interna que, sin renunciar al comercio exterior y a la interdependencia, pongan por delante la noción operativa, pero trascendente, de desarrollo como libertad e igualdad.

Frente a la ortodoxia, Fernando Fajnzylber (1992) postulaba que América Latina requiere de un sistema industrial competitivo internacionalmente, pero en un contexto de equidad.

En y frente a la crisis y la difícil recuperación que se vive, la normalidad reclama ser revisitada desde la dura experiencia de estos años, si bien regresar a la normalidad significa ir más allá de la recuperación de las tasas de crecimiento y lograr que el aparato productivo supere su recesión; involucra que se volverá a una "normalidad" distinta (Anguiano, 2012).

La experiencia nos permite y obliga a ir más allá de estas consideraciones. Lo que se impone hoy es colocar lo social como punto de partida para reordenar objetivos y visiones de la macroeconomía y del desarrollo. Esta reinversión de funciones puede probarse no solo útil para la estabilidad política, sino convertirse en una fuente renovable de actualización y profundización de la legitimidad democrática y del Estado. Pensar la política social como componente indispensable y no residual del desarrollo democrático podría volverse así empresa civilizatoria.

"La justicia social, repetimos, es inseparable del derecho al desarrollo; la noción de justicia social - postulaba Carpizo (2012), rector magnífico de la Universidad Nacional Autónoma de México (UNAM) no se encuentra en desuso (...). La fuerza especial del concepto de justicia social se encuentra en que además de su significado jurídico y constitucional, se impregna de carácter sociológico y, en particular, de un sentido de equidad". Es un derecho ciudadano y su realización debería ser una prioridad para los Estados, en la crisis y más allá de ella.

La oportunidad de una inscripción de la democracia en los objetivos del desarrollo, para adjetivarlo, parece ser la senda más segura, aunque tal vez la más ardua, para hacer factible la ambición — revigorizada por el cambio del mundo- de avance económico con profundización democrática y equidad social ligada a horizontes de igualdad. En este sentido, vale la pena reiterarlo: reasumir y revalorar las dimensiones nacionales para abordar lo global, y no para exorcizarlo, es tarea central.

Como ha dicho la filósofa española Adela Cortina (2006): "Estado democrático, economía ética y ciudadanía activa forman el trípode en el que se sustenta una sociedad desarrollada. En articular los esfuerzos de estos tres poderes —el político, el económico y el cívico—reside la piedra filosofal de los nuevos tiempos (...)".

En el pensamiento histórico fundado por Prebisch también ha sido persistente el litigio con el Estado. Desde la concepción misma del Estado moderno hasta la evaluación de sus diferentes formas intervencionistas, el Estado nunca es para la CEPAL el último recurso, pero tampoco el único. De ahí la dificultad conceptual y práctica para lidiar con el Estado, que al final de cuentas es la relación entre la sociedad y el poder. La saga es larga: del protodesarrollismo a la economía mixta y a una planificación innovadora; del gran proyecto de transformación, desarrollo e integración, al Estado acorralado y la relación amputada por la violencia pura y dura de la dictadura. De ahí despega la pretensión grotesca de una reforma radical, "revolucionaria", del Estado para rehacer el presente a partir de la reinvención de una historia engañosa: la edad de oro de un Estado mínimo y una economía de competencia perfecta que saltaría a la inserción en un ilusorio mercado mundial unificado: un falso amanecer.

Ahora nuestro aprendizaje de décadas de conflicto, penuria y adversidad se pone a prueba; la dificultad, 
entendida como linealidad que habría de superar el Estado, debe quedar atrás para asumir la complejidad inherente a la globalidad y la que es propia e insoslayable de una sociedad plural y diversa que ha hecho de la democracia la lingua franca de la política. Esta, a su vez, tiene que incorporar a su semántica los dilemas y restricciones emanados de la globalización y sus "perplejidades", como gustaba llamarlas Fajnzylber.

Esta complejidad se extiende y profundiza al encontrarse con y reconocerse en una heterogeneidad estructural que el cambio globalizador no logra modular. Lo que sí consigue es generar nuevas oleadas de excluidos y reclamos airados de inclusión que, incrustados en la ciudad y cada vez menos en el campo, cuestionan directamente al Estado, pretendidamente democrático, y exigen una representatividad y una participación acordes con un mensaje igualitario que va más allá de las urnas, propio del Estado refundado gracias a la creación de regímenes universales de bienestar. De aquí surge el binomio que condensa el reto que hoy se enfrenta: Estado y democracias difíciles, en un contexto social complejo y abigarrado, desgarrado por la desigualdad.

Hay que iniciar una nueva ronda sobre el Estado que asuma su necesidad y la del poder como una generalidad y, a la vez, reconozca la impronta idiosincrática de historias, estructuras sociales y formaciones estatales que le dan sentido y sello a la aventura bicentenaria de América Latina, en donde la idea del desarrollo vuelve a ser, sin descanso, el desarrollo de las ideas. Es mucho lo que resta por hacer para darle solidez al cambio que ahora, adjetivado por la democracia y la igualdad, puede proponerse como indispensable. En primer término, se impone contar con un esquema de decisiones y prioridades, secuencias y coaliciones que permitan gobernarlo y darle un sentido redistributivo explícito.

Asimismo, un proceso como el esbozado reclama mecanismos efectivos para detectar errores, deficiencias e insuficiencias y enmendarlos a tiempo, asumiendo la falibilidad de la conducción y la plétora de contingencias que siempre acompañan al cambio económico y social. Lo que está en juego no es tanto no fallar, sino después de ello intentarlo de nuevo para, como dijera Beckett, "fallar mejor".

"Influir sobre las fuerzas del desarrollo — afirmaba Prebisch (1963) — es de muy vastas dimensiones en tiempo y en extensión. No sólo exige la transformación de estructuras, sino también mudanzas de actitudes, de modos de ver y de formas de actuar. ¿Pero se conseguirán estas mudanzas en nuestros países? Preguntárselo entraña con frecuencia un sentido de escepticismo que desalienta la acción. Hay que empeñarse ineludiblemente en hacerlo, porque no hay otra solución".

De lo que se trataría, entonces, es de crear capacidades productivas, institucionales e intelectuales, de imaginación histórica y sociológica innovadoras, para adaptar la tecnología global y hacer que la apertura funcione en nuestro favor; en otras palabras nacionalizar la globalización, lo que en México soslayamos y hemos pospuesto sin fecha de término.

\section{VI}

\section{Una cierta mirada}

Permítaseme para terminar, arriesgar una apretada síntesis de la experiencia mexicana reciente. País frontera, México puede ser visto como el "extremo norte" de este nuestro Occidente extremo, como nos veía el estudioso embajador francés Alain Rouquié. Ahí se hizo una apuesta mayor por un cambio estructural vertiginoso, que asegurara su pronta inserción en los nuevos mundos que la globalización de fin de siglo prometía. Mucho que aprender y que enmendar, en algunos casos que remendar, nos arroja el relato mexicano de su "Gran Transformación" hacia una economía abierta y de mercado. Poco de qué ufanarse, salvo la gran disposición de la sociedad para vivir con prudencia bajo la tormenta del cambio y más que de resignación dar una prueba más de su capacidad para sobreponerse a la adversidad y tratar de afirmar la idea del desarrollo como tarea nacional.

Después de casi 30 años de búsqueda por parte del Estado y de grupos importantes y poderosos de la sociedad, de una forma diferente de crecer y desarrollarse, la economía política mexicana sufre una crisis de visión en la que se condensan los resultados de un mal desempeño económico y unas implicaciones sociales desalentadoras y dañinas para la mínima cohesión que es necesaria para la estabilidad y el desarrollo. Esta crisis, a su vez, alimenta y se retroalimenta de los varios extravíos sociales y políticos que han acompañado los cambios estructurales 
iniciados en los últimos lustros del siglo pasado y que en el presente son vistos como una temible combinación de anomia y criminalidad desbordada.

La revisión de la estrategia seguida es urgente y necesaria y debe partir por el cuestionamiento de la política económica adoptada, cuyos resultados hasta ahora han sido un crecimiento muy lento de la actividad económica, una pérdida progresiva del potencial de la economía en su conjunto, la mitad de la población en pobreza y empleos no solo precarios, sino con salarios insuficientes, muy por debajo de lo que reclama la presencia creciente y abundante de los jóvenes y adultos jóvenes en quienes ha encarnado el cambio social y demográfico del país en los últimos años. A la vez, pasar revista a la estructura democrática seguida desde finales del siglo XX, lleva a preguntarse si las formas de representación y gobierno del Estado alcanzadas son las que se requieren para dar cauce al reclamo redistributivo y desarrollista que puede avizorarse.

Las reformas cambiaron usos y costumbres, así como los formatos y las rutinas del cálculo económico, pero las dislocaciones que propiciaron no fueron interiorizadas por el cuerpo social y productivo que emergía y redundaron en un debilitamiento mayor del Estado, cuyas fallas - aparentes o inventadas- sirvieron para justificar una reforma económica a rajatabla y, luego, una reforma política por la vía exclusiva de los votos. Desde el Estado se aceleró la mudanza social y económica, pero no se hizo lo necesario para modularla, atemperar sus inevitables dislocaciones y proteger a los sectores, regiones y grupos sociales más débiles.

No se trata de regatear los logros del cambio: en menos de 20 años México se volvió un gran exportador de manufacturas pesadas y semipesadas, con una base poderosa de la producción y la exportación automotriz y electrónica. En conjunto, sus ventas al exterior se multiplicaron por cinco. También, superó su condición de economía casi monoexportadora, dependiente en alto grado de las ventas foráneas de petróleo crudo.

$\mathrm{Al}$ calor de estas transformaciones en su estructura comercial, México atrajo montos considerables de inversión extranjera directa. En muy poco tiempo, el país se volvió uno de los tres principales socios comerciales de los Estados Unidos de América y apareció en la escena comercial mundial como un nuevo y atractivo jugador de grandes ligas.

También puede presumirse que, a pesar de su lentitud, la reforma política rindió al final frutos considerables. Las cámaras del Congreso de la Unión diversificaron su contenido político e ideológico, reprodujeron la pluralidad y le dieron una nueva faz y color al sistema político que derivó en un pluripartidismo activo y activista. Además, se levantaron los diques de un federalismo siempre contenido y desnaturalizado por el poder central y se entró en la fase, que no ha terminado, de una regionalización y una descentralización feroz, casi salvaje, que sin embargo, ha sido capaz de volverse una fuente de poder político plural decisiva dentro del actual Estado nacional.

Frente a esto, habría que preguntarse ahora si un país con el tamaño económico del de México, con la riqueza generada y acumulada, con las instituciones y el conocimiento tan difícilmente labrados, puede darse el lujo de registrar y reproducir un "estancamiento estabilizador" como el que se ha impuesto, junto con las cuotas de desigualdad y las magnitudes de pobreza que lo marcan. Debajo de estas disonancias, opera una persistente incapacidad para vincular productivamente una demografía transformada — dominada ahora por jóvenes y adultos jóvenes urbanos y en edad de trabajar y estudiar - y una economía también transformada, abierta y diversificada, pero que no ha podido generar, a lo largo de más de tres décadas, los empleos y los espacios educativos necesarios para absorber productivamente a la población.

La travesía mexicana recoge excesos y errores, tanto en lo económico como en lo social, así como en las ideas sobre el cambio y la forma de gobernarlo y conducirlo a buen y seguro puerto. Los principales diques para realizar la reconversión necesaria, no solo en México, provienen de los fundamentalismos que se impusieron en la conducción de la política económica y contagiaron a importantes grupos de poder, así como de la opinión pública. El dogma de mantener a toda costa unos supuestos equilibrios macroeconómicos, constreñidos a elementales restricciones externas e internas, condujeron a las élites políticas y económicas a impulsar políticas y acciones que respondieran irrestrictamente a las versiones ortodoxas de observación y mantenimiento de dichos equilibrios.

Hay que insistir que el mal desempeño económico de largo plazo no es efecto solo, ni principalmente, de un desajuste de los mercados internacionales. Debe entenderse, más bien, como un resultado de decisiones políticas y económicas que han hecho caso omiso de otros "fundamentales", como la necesidad de inversión física sostenida para el crecimiento a largo plazo, de una política industrial dirigida a diversificar y crear nuevas cadenas productivas para apropiarse de la renta externa, así como poner en el centro de la atención y acción del Estado la superación de la pobreza y el abatimiento consistente de la desigualdad.

Lo que está en primer lugar de la orden del día del desarrollo económico mexicano es reconfigurar sus funciones básicas y poner al empleo como objetivo 
central y articulador de una estrategia para la expansión con y para la igualdad. El estancamiento histórico relativo que aqueja al país de las revoluciones y de la construcción nacional a contrapelo de los supuestos mandatos universales de la historia, solo podrá superarse trazando un nuevo curso donde se rearticulen medios y objetivos y se contemple la necesidad imperiosa de formas novedosas de participación social y política en las deliberaciones y decisiones del Estado. Alcanzar plataformas superiores de cooperación entre fuerzas sociales, grupos productivos y regiones, que combinen la democracia con la movilización colectiva, permitirá redefinir los linderos entre lo público y lo privado, sin sacrificar o posponer sine die la hora de la igualdad, y

\section{VII}

\section{Conclusiones}

Las disonancias que la globalización ha hecho emerger y que la crisis ha agudizado entre apertura externa, soberanía de los Estados y las naciones y democracia, llevan a insistir en la necesidad de abordar, con sentido de urgencia, tales disonancias. Estas tensiones tienen lugar en contextos sociales complejos, desgarrados por la desigualdad; frente a todo esto es indispensable recuperar el desarrollo entendido como proceso central y global. Estas son restricciones estructurales, valorativas e ideológicas que el planeta debe encarar para dar lugar a formas evolutivas en el orden económico y político, que permitan encontrar nuevas ideas y utopías organizadas en torno de (y sostenidas por) el desarrollo.

Toda la evolución y las reformas institucionales que reclama el rescate del desarrollo implican asumirlo, poder montar, ahora bajo los mandatos de la restricción democrática, una conversación virtuosa entre acumulación y redistribución, como se arriesgó a intentarlo el Presidente Lázaro Cárdenas al frente de la coalición popular que cubrió de gloria al país y su revolución.

De lo que se trata — para salir de este híbrido laberinto de la "soledad abierta" en que nos encontramos (pero que continúa barrocamente el que nos dibujara Octavio Paz), donde la modernidad se ha confundido con el más ingenuo y leve de los cosmopolitismos-es de contribuir a definir, parafraseando a don Alfonso Reyes, "como posible campo donde realizar una justicia más igual, una libertad mejor entendida (...) una soñada República, una Utopía” (Martínez, 2012). explícitamente, como un proceso complejo, político y social, además de económico. La idea del desarrollo que pueda resultar de esta dialéctica no podrá desentenderse del papel preponderante que la política y el Estado tienen en su despliegue. De aquí la centralidad que para una idea histórica y actual del desarrollo tienen la noción de cambio social y el imperativo de asumir el aprendizaje y la pedagogía democráticas como vectores insustituibles del proceso en su conjunto.

Este es el contexto donde habrá de dirimirse la confección de estrategias y políticas, así como las diversas opciones de inserción en la economía mundial que se abran, o deberían hacerlo, para las naciones que pugnan por apropiarse de la idea del desarrollo, como realidad y como utopía. 


\section{Bibliografía}

Anguiano, Eugenio (2012), Mercados financieros internacionales. Su historia, evolución y crisis, México, D.F., Universidad Nacional Autónoma de México (UNAM)

Bobbio, Norberto (1991), El tiempo de los derechos, Madrid, Fundación Sistema.

Bottomore, Tom y T.H. Marshall (2005), Ciudadanía y clase social, Buenos Aires, Editorial Losada.

Carpizo, Jorge (2012), "El estado de los derechos de la justicia social", Revista Latinoamericana de Derecho Social, $\mathrm{N}^{\circ} 14$, México, D.F., Universidad Nacional Autónoma de México (UNAM), enero-junio.

CEPAL (Comisión Económica para América Latina y el Caribe) (2012), Cambio estructural para la igualdad: Una visión integrada del desarrollo (LC/G.2524(SES.34/3)), Santiago de Chile.

(2010), La hora de la igualdad: Brechas por cerrar, caminos por abrir (LC/G.2432(SES.33/3)), Santiago de Chile.

(2000), Equidad, desarrollo y ciudadanía, Bogotá, AlfaOmega.

Cortina, Adela (2013), "Cómo cambiar la tendencia", El país, 23 de enero.

(2006), "Ética del desarrollo: Un camino hacia la paz", Sistema, $\mathrm{N}^{\circ} 192$.

Dosman, Edgar (2011), "El regreso de Raúl Prebisch", Homenaje a Raúl Prebisch (1901-1986) (LC/G.2499), Alicia Bárcena, Edgar Dosman y Osvaldo Súnkel, Santiago de Chile, Comisión Económica para América Latina y el Caribe (CEPAL) [en línea] http://www.eclac.org/publicaciones/xml/9/48009/ HomenajeRaulPrebisch-Osvaldo.pdf.

(2001), "Los mercados y el Estado en la evolución del 'manifiesto' de Prebisch", Revista de la CEPAL, $\mathrm{N}^{\circ} 75$ (LC/G.2150-P), Santiago de Chile, diciembre.

Fajnzylber, Fernando (1992), "Industrialización en América Latina: de la "caja negra' al casillero vacío", Nueva Sociedad, $\mathrm{N}^{\circ} 118$, marzo-abril.

Ferrer, Aldo (2010), "Raúl Prebisch y el dilema del desarrollo en el mundo global", Revista de la CEPAL, $\mathrm{N}^{\circ} 101$ (LC/G.2455-P), Santiago de Chile, agosto.

Furtado, Celso (2004), Revista Pesquisa, № 106, Fundación para la Defensa de las Investigaciones del Estado de São Paulo
(FAPESP), diciembre [en línea] http://revistapesquisa.fapesp. br/es/2004/12/01/la-fantasia-deshecha/.

Galbraith, John Kenneth (2011), La cultura de la satisfacción, Madrid, Ariel.

Halperin, Tulio (2008), "La CEPAL en su contexto histórico", Revista de la CEPAL, $\mathrm{N}^{\circ} 94$ (LC/G.2357-P), Santiago de Chile.

Martínez, José Luis (2012), América en el pensamiento de Alfonso Reyes, México, D.F., Fondo de Cultura Económica.

Moreno Brid, Juan Carlos (2013), "Política macroeconómica para el desarrollo", EconomíaUNAM, № 30, México, D.F., Universidad Nacional Autónoma de México (UNAM), septiembre-diciembre.

Ocampo, José Antonio (2011), "Macroeconomía para el desarrollo. Políticas anticíclicas y transformación productiva", Revista CEPAL, $\mathrm{N}^{\circ} 104$ (LC/G.2498-P), Santiago de Chile, agosto.

(2001), "Retomar la agenda del desarrollo", Configuraciones, N 5-6, México, D.F., Instituto de Estudios para la Transición Democrática (IETD), octubre-diciembre.

PNUD (Programa de las Naciones Unidas para el Desarrollo) (2004), La democracia en América Latina. Hacia una democracia de ciudadanos y ciudadanas, Buenos Aires, Alfaguara.

Polanyi, Karl (1992), La gran transformación. Los orígenes políticos y económicos de nuestro tiempo, México, D.F., Fondo de Cultura Económica.

Prebisch, Raúl (1963), Hacia una dinámica del desarrollo latinoamericano, México, D.F., Fondo de Cultura Económica.

Ros, Jaime (2013), "Repensar el desarrollo económico, el crecimiento y las instituciones", Economíaunam, $\mathrm{N}^{\circ}$ 30, México, D.F., Universidad Nacional Autónoma de México (UnAM), septiembre-diciembre.

Rosanvallon, Pierre (1989), "Development of Keynesianism in France", The Political Power of Economic Ideas: Keynesianism across Nations, Peter Hall (ed.), Nueva Jersey, Princeton University Press.

Sen, Amartya (2003), Ponencia presentada en el Seminario Internacional "Ética y desarrollo", Banco Interamericano del Desarrollo.

Smith, Adam (1794), Investigación sobre la naturaleza y causas de la riqueza de las naciones, Valladolid.

Wolfe, Marshall (1976), El desarrollo esquivo, México, D.F., Fondo de Cultura Económica. 